\title{
Effects of a Digital Mental Health Program on Perceived Stress in Adolescents Aged 13-17 Years: Protocol for a Randomized Controlled Trial
}

Eliane M Boucher, PhD; Haley E Ward, BA; Julia L Stafford, BSc; Acacia C Parks, PhD

Happify Health, New York, NY, United States

\section{Corresponding Author:}

Eliane $\mathrm{M}$ Boucher, $\mathrm{PhD}$

Happify Health

51 East 12th Street, 5th Floor

New York, NY, 10003

United States

Phone: 14322585233

Email: eliane@happify.com

\begin{abstract}
Background: Stress is an important transdiagnostic risk factor in adolescence and predicts a host of physical and psychological problems in adolescence and adulthood. Adolescence is also a developmental stage in which people may be more sensitive or reactive to stress. Indeed, research has shown that adolescents report high levels of stress, particularly when enrolled in school. However, adolescents report engaging in few, if any, stress management techniques. Consequently, the development of effective programs to help address adolescent stress is particularly important. To date, most stress management programs for adolescents are delivered within schools, and the evidence for such programs is mixed. Furthermore, most of these programs rely on traditional stress management techniques rather than incorporating methods to address the underlying negative cognitive processes, such as rumination, that may contribute to or exacerbate the effects of perceived stress.
\end{abstract}

Objective: The aim of this study is to test the short-term effects of a digital mental health program designed for adolescents aged 13-17 years on perceived stress and rumination.

Methods: This is a randomized controlled trial in which adolescents between the ages of 13 and 17 years, with elevated levels of perceived stress and brooding, will be randomly assigned to complete 8 weeks of a digital mental health program (Happify for Teens) or to a corresponding wait-list control group. The study will take place over 3 months, including the 8 -week intervention period and 1-month postintervention follow-up. The primary outcome, perceived stress, along with secondary and exploratory outcomes (ie, brooding, optimism, sleep disturbance, and loneliness) will be assessed via self-report at baseline, 4 weeks, 8 weeks, and 12 weeks to compare changes in these outcomes across conditions.

Results: Recruitment is expected to begin in the second quarter of 2021, with a target sample size of 800 participants (400 per condition). Participants will begin the study as they are recruited and will finish in waves, with the first wave of data expected 8 weeks after recruitment begins and the final wave of data expected by the end of the third quarter of 2021.

Conclusions: Although school-based stress management programs for adolescents are common, research suggests that they may be limited in their reach and more effective for school-based stress than other types of stress. This trial will be one of the first attempts to examine the potential benefits of a digital mental health program on adolescents to address stress along with negative cognitive processes such as rumination. If successful, this would help introduce a more scalable alternative to school-based programs that offers adolescents greater privacy while also providing insight into novel ways to target adolescent mental health more generally.

Trial Registration: ClinicalTrials.gov NCT04567888; https://clinicaltrials.gov/ct2/show/NCT04567888

International Registered Report Identifier (IRRID): PRR1-10.2196/25545

(JMIR Res Protoc 2021;10(4):e25545) doi: 10.2196/25545

\section{KEYWORDS}

digital intervention; adolescents; stress management; mental health; mobile phone 


\section{Introduction}

\section{Background}

In the United States, approximately $16.5 \%$, or 7.7 million, adolescents have at least one mental health disorder [1]. Worldwide, approximately $10 \%-20 \%$ of adolescents struggle with mental health problems [2]. Importantly, the rates of mental illness have increased among adolescents in recent years [3] and at steeper rates than among adults [4]. Given that the onset of many mental health disorders occurs in childhood and adolescence, which often continue into adulthood [5,6], addressing mental health in adolescence is a key factor for reducing the prevalence of mental health disorders in adulthood.

Despite several public health efforts to increase access to mental health services for youth, service utilization by adolescents with mental health disorders remains low [7]. Only 50\% of American adolescents with mental illness seek mental health treatment [1], and only $36.2 \%$ actually receive treatment [7]. The number of adolescents receiving treatment for internalizing disorders, such as anxiety and depression, is even lower [7,8]. Paradoxically, national trends indicate that, overall, adolescent use of outpatient mental health services, including both psychotherapy and psychotropic medications, has increased over time [9]. However, this increase is primarily attributed to adolescents with less severe or no mental health impairment [9]. This is problematic given the shortage of mental health service providers for children and adolescents, particularly in rural and low-income areas [10]. The increased use of these services by adolescents in general likely places a strain on the available services for youth, and, in turn, adolescents with more serious mental health disorders may have more trouble receiving necessary treatment.

\section{Mental Health Prevention Programs for Adolescents}

Although discussions of mental health often focus on dysfunction, more recently, there has been a call for a definition of mental health that considers more than the mere absence of mental illness [11]. For example, Keyes [12] argued for a distinction between languishing, or the absence of mental health, and flourishing, or the presence of mental health. In other words, mental health also encapsulates positive or protective features, including well-being, optimal prosocial functioning, emotion regulation, empathy, and resilience [11,13]. Consequently, addressing mental health concerns in adolescents should also include efforts to promote flourishing, as this may help to reduce the likelihood of future dysfunction [13].

However, there has been more attention on mental health treatment in youth than on prevention [2]. Given the strain on mental health services for youth from adolescents with less severe or no impairment, interventions focused more on promoting flourishing and preventing future dysfunction and impairment are important [13]. Such programs can be universal, which are directed at all adolescents and often offered in schools, or targeted, in that they focus on adolescents who are at risk of more severe impairment [2]. Both universal and targeted programs can help address the growing interest in mental health services by adolescents while reserving more intense treatment programs for youth with mental illness, for whom prevention programs are not sufficient [13]. In particular, interventions that target transdiagnostic risk factors, which predict the onset and maintenance of multiple disorders [14], are likely to have the greatest effect in terms of preventing future dysfunction $[15,16]$.

Research suggests that these prevention programs have both concurrent and long-term benefits for mental health, particularly when they target specific risk and protective factors for adolescent mental health $[2,17]$. For example, universal resilience-based interventions delivered in schools reduce internalizing symptoms in adolescents aged 11-18 years [18]. In another study, students who were offered a universal, positive psychology intervention reported significant reductions in distress, anxiety, and depressive symptoms, whereas students who were not offered this intervention reported increases in all these outcomes [19]. Targeted prevention programs based on cognitive behavioral therapy (CBT) have also been shown to have short-term effects on depressive symptoms [20,21] and improve self-efficacy and academic achievement in adolescents [22].

\section{Stress as a Risk Factor in Adolescence}

Over the past decade, researchers have become increasingly interested in adolescent stress as a transdiagnostic risk factor because of its prevalence and its association with internalizing and externalizing disorders [23-25] as well as a host of other negative consequences, including poorer physical and academic outcomes. Adolescence is also a developmental stage where individuals may be particularly sensitive to stress due to shifts in hypothalamic-pituitary-adrenal axis reactivity, leading to more intense hormonal responses to stressors, particularly in older adolescents [26].

Although animal models suggest that predictable, chronic mild stress levels in adolescence can actually increase resilience in adulthood [27], research suggests that many adolescents are coping with more severe stress levels. For example, in one study, $22 \%$ of adolescents aged 15-17 years reported moderate to severe levels of perceived stress [28]. In addition, a national survey conducted by the American Psychological Association (APA) in 2013 found that adolescents reported higher levels of stress than they perceived to be healthy and that their stress levels during the school year exceeded those of adults [29]. In addition, $31 \%$ of these adolescents reported that their stress levels had increased over the previous year, whereas $34 \%$ believed that these would increase over the following year [29]. These high stress levels may reflect a variety of stressors in adolescence. Qualitative interviews with adolescents suggest that they perceive their stress to stem from family and academic sources as well as role transitions and societal problems [30]. Quantitative research corroborates these accounts, suggesting that adolescents' primary sources of stress are school and arguments at home [31]. In fact, adolescents report higher levels of stress during the school year than during the summer, with more than twice as many adolescents reporting extreme levels of stress during the school year than during the summer break [29].

Regardless of the source, such high levels of stress can have deleterious effects on adolescents' psychological and physical health, including lower life satisfaction [32], poorer academic 
performance [33,34], cigarette smoking [35], emotional eating [36], poorer diet [37], and more frequent subjective health complaints (eg, headaches, fatigue, and sleep difficulties) [38]. Stress in adolescence has also been linked to internalizing symptoms, including depression [23,24] and anxiety [24]. Interpersonal stress, in particular, predicts the onset of the first major depressive episode among adolescents [39]. Thus, addressing stress in adolescents is critical for avoiding long-term problems. Although the frequency of stressful or negative life events predict negative outcomes [35,39], adolescents' cognitive appraisal of these events, that is, their perceptions of stress, also predicts negative outcomes [32,36-38]. Perceived stress may be more strongly tied to negative outcomes than to life events alone [40].

However, adolescents tend not to believe that stress negatively affects their mental health, and most do not engage in regular stress management [29]. Approximately 55\% of adolescents report setting aside time for stress management only "a few times a month or less," $13 \%$ report never setting aside time for stress management, and only 5\% report having seen a mental health professional about their stress [29]. On the basis of these data, the APA noted the need for opportunities to help adolescents address and cope with their stress "to break this unhealthy legacy of stress in America" [29].

Although there has been an increase in interventions targeting perceived stress in adolescence [41], they are much less common than those for anxiety and depression [42]. Furthermore, most interventions for stress are school-based, and the evidence for these interventions is mixed. In a systematic review of stress management interventions, only $58 \%$ of the reviewed studies found significant improvements in physiological indicators of stress (eg, blood pressure) or self-reported stress [43]. More recent meta-analyses of school-based programs suggest that the benefits may be limited to targeted samples (eg, with high levels of stress) and not universal programs [41,42] and may only be effective for school rather than social stress [41]. Given these findings, we need more research exploring the effectiveness of stress management programs, particularly those that could be delivered outside schools.

\section{Negative Cognitions and Stress}

Research suggests that stress in adolescence stems, at least in part, from feelings of helplessness and negative affect [44] Therefore, effective interventions for adolescent stress may need to target the underlying negative cognitions as well as perceived stress. However, recommended approaches to addressing stress tend to focus on stress management training, relaxation training, and problem-solving and decision-making skills training $[16,41,42]$, which may not adequately address the related negative cognitions.

Indeed, there is evidence that improving the content of adolescents' cognition can help mitigate the negative effects of stress. For example, interpersonal stress predicts depressive symptoms in adolescents only when coupled with negative cognitions [39] or persistent low positive affect [45], whereas self-compassion buffers against the negative effects of perceived stress on internalizing symptoms [24]. In other words, addressing both negative cognitions and stress together may be particularly important in mitigating the negative consequences of stress [39].

The cognitive processes related to these negative cognitions may also be relevant. Rumination is a pattern of thinking in which individuals repeatedly think about the causes, consequences, and symptoms of their negative affect and often occurs following stressful events [46]. Rumination can be beneficial, where the individual engages in reflective pondering, or harmful, where the individual engages in brooding or moody pondering [47]. Similar to stress, rumination is another important transdiagnostic risk factor in prevention interventions for adolescents, as it predicts a host of other problems [48,49]. In adolescents, rumination, and particularly brooding, predicts depressive symptoms [50,51], anxiety [52], executive functioning impairments in selective attention and attentional switching [53], substance use problems [54], posttraumatic stress disorder following traumatic events such as terrorist attacks [55], and less sleep [48]. Furthermore, rumination and psychological distress appear to be involved in a cyclical pattern whereby ruminative thinking leads to psychological distress, which then predicts more rumination [48].

As rumination can occur in response to stressful events, it also plays a role in the negative consequences of chronic stress. For instance, longitudinal research has shown that more frequent stressful life events predict increased rumination among both adults and adolescents and that rumination mediates the relationship between stressful life events and anxiety symptoms in adolescents [56]. Other studies have shown that adolescents who ruminate in response to stress are at a greater risk of depression and substance misuse [57]. In college students, stress-reactive rumination, but not momentary ruminative self-focus, predicted depressive symptoms, although both predicted depressive symptoms among students with higher levels of stress [58].

In addition to contributing to the negative effects of stress, rumination may increase perceived stress. In one study, rumination exacerbated the relationship between life hassles and depression, anxiety, and stress in adolescents [59]. Rumination also increases adolescents' likelihood of experiencing interpersonal stress, which in turn predicts more internalizing symptoms [60]. Therefore, applying more traditional approaches such as cognitive restructuring, self-monitoring, acceptance strategies, and attention control training [16] to address negative cognitive processes such as rumination may be helpful in reducing stress as well.

Unfortunately, aside from studies specifically testing stress management interventions, few intervention studies have included stress as an outcome variable [42]. To the best of our knowledge, no intervention research has focused on stress and rumination together. However, research suggests that similar approaches might be effective for reducing both stress and rumination. For example, researchers posit that mindfulness helps prevent depression by promoting low levels of rumination and high levels of self-compassion [61]. Indeed, trait mindfulness mitigates the relationship between life hassles and depression, anxiety, and stress [59], and mindfulness-based interventions have been shown to reduce perceived stress and 
increase self-compassion in middle school students [62]. Cross-sectional research with college students also suggests that self-compassion attenuates the effects of rumination on stress [63], and increases in self-compassion following intensive meditation retreats predict improvements in perceived stress, rumination, negative affect, and depressive symptoms [64]. CBT has also been used successfully for both rumination $[49,65]$ and perceived stress [66], although both outcomes have never been measured together. These findings suggest that there may be a common pathway for reducing both rumination and perceived stress in adolescents. Therefore, identifying interventions that can address both would be beneficial as they would target two, rather than one, important transdiagnostic risk factors in this population.

\section{Objectives}

The aim of this study is to test the effects of a digital mental health program that draws on several approaches to address perceived stress and rumination in adolescents. Happify for Teens is a version of the Happify Health platform that has been modified for those aged between 13 and 17 years. As in the adult version, Happify for Teens consists of gamified versions of evidence-based activities adapted from CBT [67], mindfulness-based stress reduction [68], positive psychology [69-71], behavioral activation [72,73], acceptance and commitment therapy [74], and psychoeducation [75]. Thus, Happify Health programs integrate a variety of recommended approaches to address negative cognitions [16] that appear to have promising effects for reducing perceived stress as well $[62,66,76,77]$.

Although Happify for Teens has yet to be tested empirically, research on the adult version demonstrates that Happify Health programs lead to significant improvements in mental health. Observational studies of existing Happify Health users found significant improvements in subjective well-being after 6-8 weeks of use, with greater gains among users who completed more activities [78-80]. Similarly, participants in randomized controlled trials (RCTs) who completed at least two activities per week had significant improvements in depressive symptoms, anxiety, and resilience compared with participants in a psychoeducation control group or participants who completed less than 2 Happify Health activities per week [81,82].

Notably, although published analyses did not examine the effect of Happify Health on perceived stress directly, perceived stress was included as 1 of 3 components for a resilience index, which significantly decreased in users who competed at least two activities per week for 8 weeks [81,82]; unpublished data indicate that perceived stress specifically decreased along with resilience (Parks, AC, unpublished data, December 2018). In addition, experimental research suggests that using one of the activities within the Happify Health platform, a heart rate variability biofeedback game, following a stressful event may help users manage their stress, as evidenced by lower salivary alpha amylase in participants who completed this activity relative to controls [83]. These data suggest that Happify for Teens may help adolescents manage their stress while providing the added benefit of addressing underlying negative cognitions and cognitive processes.
To test the effect of Happify for Teens on perceived stress in adolescents, we plan to recruit adolescents aged 13-17 years who report elevated levels of perceived stress and rumination. Participants will be randomly assigned to complete 8 weeks of activities via Happify for Teens or to a corresponding wait-list control group. We will then compare changes in perceived stress at 4 weeks, 8 weeks, and 1 month post intervention across the 2 groups. We will also examine changes in brooding (the maladaptive component of rumination) as a secondary outcome. Finally, as sleep disturbance [84,85], optimism [86,87], and loneliness [88,89] have been identified as other potential transdiagnostic risk factors for future mental health impairment that may begin in adolescence, we also examined changes in sleep disturbance, optimism, and loneliness as additional exploratory outcomes.

\section{Methods}

\section{Participants}

This study is an RCT (NCT04567888) with a target sample size of 800 participants (400 participants per condition). Power analyses indicated that 200 participants (100 per condition) would be sufficient for $80 \%$ power to detect a small effect; however, attrition rates for this study are difficult to predict. Previous RCTs using Happify Health with adult participants had response rates ranging from $56 \%$ to $72 \%$ for an 8 -week intervention and posttest $[81,82]$. Research on other digital interventions with adolescents has reported substantial variability in completion rates. The levels of noncompletion for internet-based CBT interventions range from $33.3 \%$ to $69.6 \%$, with low use rates overall [90], whereas for digital interventions targeting diet and physical activity, completion rates range from $37 \%$ to $100 \%$ [91]. On the basis of this variability, we opted for a conservative approach to ensure adequate power and estimated a $75.0 \%(600 / 800)$ attrition rate, leading to an initial target sample size of 800 adolescents to maintain adequate power.

\section{Recruitment}

To recruit participants, we will advertise the study to existing Happify Health users who indicate that they have adolescent children. In addition, to target parents (and adolescents) less familiar with the platform, we will also advertise the study using targeted advertising on social media. Finally, we will distribute information about the study in 2 public schools (one located in California and another in Montana) that contacted Happify Health about the program. Representatives from these schools who contacted our research staff to express interest in the product will distribute letters to parents within their schools, with information about the study and a link to the parent prescreening survey.

Regardless of the recruitment method, interested parents will be directed to complete a brief screening questionnaire via Qualtrics to verify that their child is aged between 13 and 17 years, resides in the United States, and has never used Happify Health before. After meeting the initial eligibility criteria, parents will provide consent for each eligible child to participate in the study. In addition, we plan to use a snowballing recruitment method whereby parents who complete this 
screening questionnaire will be encouraged to share the study with other parents, and they will be entered into a drawing for a US \$50 Amazon gift card for each parent they refer to the screening questionnaire.

We will then send eligible adolescents an email invitation to complete a separate screening questionnaire via Qualtrics, consisting of questions regarding their age, country of residence, previous Happify Health use, and about the study procedures to confirm their eligibility for the study. Respondents will also complete the Perceived Stress Scale (PSS) [40] and Ruminative Response Scale (RRS)-Short Form-Brooding Subscale [47]. Adolescents will be eligible to participate if they are aged between 13 and 17 years, currently reside in the United States, have never used Happify Health, report elevated levels of stress (ie, PSS score >14) and rumination (ie, RRS-Brooding Subscale score $\geq 10$ ), and indicate that they are willing and able to complete the study activities. Participants from the same household will be permitted to participate in the study but will be instructed not to discuss the study or the platform with each other.

\section{Compensation}

Participants will be compensated with US \$20 for completing each of the 4-week, 8-week, and 1-month postintervention assessments. Participants who complete all 4 assessments (baseline and 3 other assessments) will receive a US $\$ 20$ bonus. Thus, participants will receive up to US $\$ 80$ as compensation for their time; participants will be compensated in the form of an electronic gift card.

\section{Primary Outcome Measure: PSS}

The PSS [40] is a widely used measure of the extent to which respondents view their lives as unpredictable, uncontrollable, or overloaded and has been used with adolescents in other studies [92,93]. It consists of 10 items asking participants the extent to which they have felt each of the feelings and thoughts in the previous month (eg, "In the last month, how often have you felt nervous and 'stressed'?"), and items are rated on a scale from 0 (never) to 4 (very often). Ratings are summed so that higher scores indicate greater perceived stress.

\section{Secondary Outcome Measure: RRS-Short Form-Brooding Subscale}

The brooding subscale of the RRS [47] examines the extent to which respondents engage in moody pondering and has been validated with adolescents [94,95]. Participants indicate how often they engage in each of the 5 behaviors (eg, "Think 'Why can't I handle things better?"') on a scale from 1 (almost never) to 4 (almost always). For this study, instructions were modified so that participants can indicate the extent to which they engaged in these behaviors during the previous month. Ratings are summed so that higher scores indicate that participants engaged in more brooding during that time.

\section{Exploratory Outcome Measures}

\section{Life Orientation Test-Revised}

The Life Orientation Test-Revised is a 10-item measure of optimism [96] that has been used with adolescents [97].
Participants indicate the extent to which they agree with each statement (eg, "In uncertain times, I usually expect the best") on a 5-point scale, ranging from 0 (strongly disagree) to 4 (strongly agree). A total of 4 items are filler items, and ratings on the remaining 6 items can be summed to obtain an overall optimism score so that higher scores indicate more optimism.

Patient-Reported Outcomes Measurement Information System Pediatric Sleep Disturbance Scale-Short Form $4 a$

This is a 4-item scale measuring the extent to which participants experienced sleep disturbances over the past 7 days (eg, "In the past 7 days, I had trouble sleeping"), appropriate for respondents aged between 8 and 17 years [98]. Each item is rated on a scale from 1 (never) to 5 (always), and ratings are summed so that higher scores indicate more sleep disturbance or poorer sleep quality.

\section{Roberts UCLA Loneliness Scale-8}

The Roberts UCLA Loneliness Scale-8 [99] was adapted from the original 20-item UCLA loneliness scale [100] for use with adolescents. It consists of 8 items (eg, "I lack companionship"), and participants indicate how often each of the statements are descriptive of them on a 4-point scale from never (0) to often (3). Ratings are summed so that higher scores indicate higher levels of loneliness.

\section{Usage Statistics}

In addition to self-reported outcomes, we also plan to collect data on usage and engagement via the Happify Health platform for those assigned to the intervention condition. Specifically, we will passively collect information about the activities completed and the number of active days.

\section{Procedure}

This study will take place over approximately 3 months, including an 8-week intervention period and a 1-month follow-up. See Table 1 for the schedule of activities. All study procedures were reviewed and approved by IntegReview, an independent institutional review board.

After obtaining parental consent, eligible participants will be contacted via email with instructions to complete an electronic assent form and the baseline assessment. This assessment will include all primary, secondary, and exploratory outcome measures. To assess data quality, we plan to include an attention check within each questionnaire in the baseline assessment and subsequent assessments. These attention checks will instruct participants to select a specific response option to determine whether participants are reading items carefully (eg, for the PSS, an attention check item could instruct the participant to select Never).

Once participants have completed the baseline assessment, they will be randomly assigned to either the intervention group or the wait-list control group and will receive further instructions via email. Participants who do not complete the baseline assessment will not be assigned to a condition and will be disqualified from the study. Similarly, participants who fail all 
attention checks within the baseline assessment will not be assigned to a condition and will be disqualified from the study.

Participants in both conditions will receive emails or text messages throughout the study to check in and keep them engaged. At 4, 8, and 12 weeks ( 1 month post intervention), all participants will also be prompted to complete all primary, secondary, and exploratory measures via Qualtrics. At each assessment, participants will also be asked to indicate whether they participated in any other interventions or used any digital self-help or wellness program since the last assessment date. Participants will receive reminders if they have not completed these assessments on time, and if a participant has not completed an assessment within 7 days of its scheduled date, a member of the research team will reach out via text message or email to check in.

Table 1. Schedule of activities for prescreen, intervention period, and follow-up assessments.

\begin{tabular}{|c|c|c|c|c|c|}
\hline \multirow[t]{2}{*}{ Assessments } & \multicolumn{5}{|l|}{ Time } \\
\hline & Prescreen & Baseline & $\begin{array}{l}\text { Week 4: mid- } \\
\text { point assessment }\end{array}$ & $\begin{array}{l}\text { Week 8: postinter- } \\
\text { vention assessment }\end{array}$ & $\begin{array}{l}\text { Week 12: 1- } \\
\text { month follow-up }\end{array}$ \\
\hline \multicolumn{6}{|l|}{ Primary outcome } \\
\hline Perceived Stress Scale & $\boldsymbol{\Omega}^{\mathrm{a}}$ & $\checkmark$ & $\checkmark$ & $\checkmark$ & $\checkmark$ \\
\hline \multicolumn{6}{|l|}{ Secondary outcome } \\
\hline $\begin{array}{l}\text { Ruminative Responses Scale-Short Form-Brooding } \\
\text { Subscale }\end{array}$ & $\checkmark$ & $\checkmark$ & $\checkmark$ & $\checkmark$ & $\checkmark$ \\
\hline \multicolumn{6}{|l|}{ Exploratory outcomes } \\
\hline Life Orientation Test-Revised & $-\mathrm{b}$ & $\checkmark$ & $\checkmark$ & $\checkmark$ & $\checkmark$ \\
\hline $\begin{array}{l}\text { Patient-Reported Outcomes Measurement System Pe- } \\
\text { diatric Sleep Disturbance Scale-Short Form } 4 a\end{array}$ & - & $\checkmark$ & $\checkmark$ & $\checkmark$ & $\checkmark$ \\
\hline Roberts UCLA Loneliness Scale & - & $\checkmark$ & $\checkmark$ & $\checkmark$ & $\checkmark$ \\
\hline
\end{tabular}

${ }^{\mathrm{a}}$ Indicates that the outcome was assessed at this time.

${ }^{\mathrm{b}}$ Indicates that the outcome was not assessed at this time.

\section{Intervention Group: Happify Health for Teens}

Participants assigned to the active intervention will receive instructions to download Happify Health and then be directed into the Teens platform after creating an account. The Happify for Teens platform was developed using the same model as the original Happify Health platform; intervention activities are organized into 6 different skills: savor (mindfulness skills), thank (gratitude), aspire (optimism, goal-setting, and finding meaning or purpose), give (kindness, forgiveness, and prosocial behavior), empathize (self-compassion and perspective-taking), and revive (physical health). However, for the adolescent platform, these activities were modified and then reviewed by a panel of adolescents to ensure that the language and content were relevant to that population (Figure 1).

Figure 1. Screenshot of Happify for Teens.

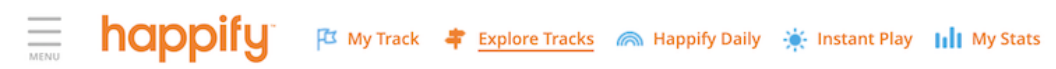

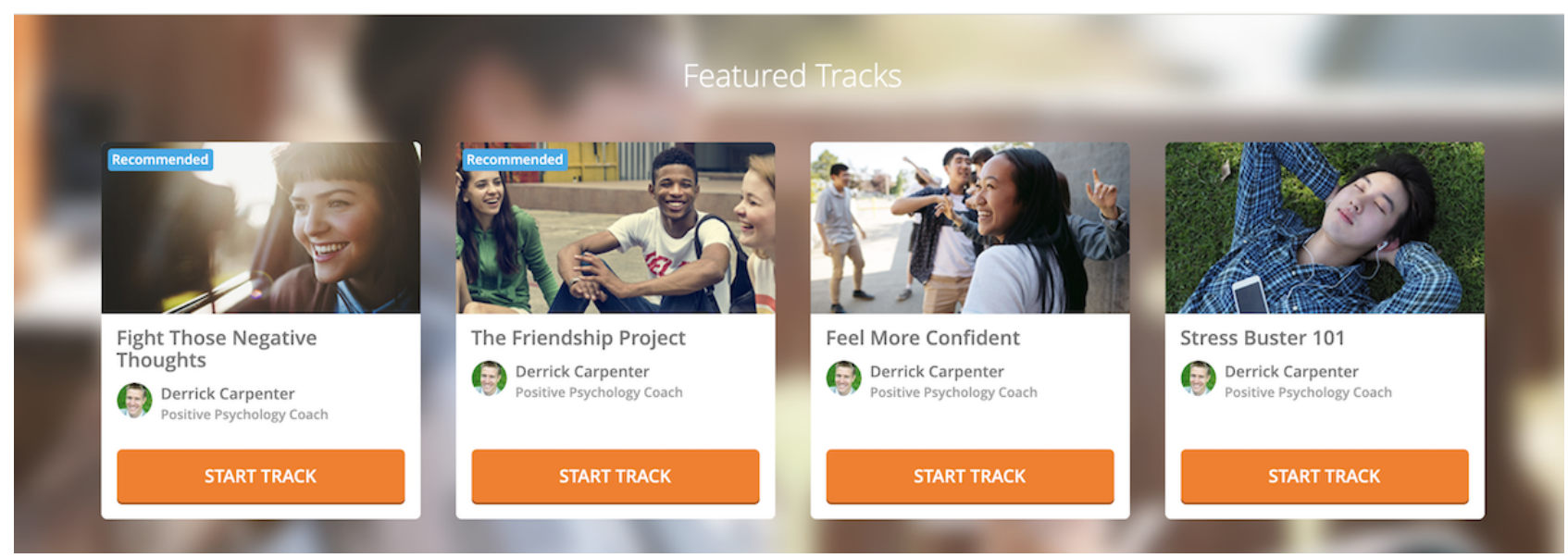

Activities from different categories are then organized into tracks focused on addressing a specific area of concern, such as increasing confidence or reducing negative thinking (see
Figure 2 for a sample track description). Users can select a track that interests them, and within each track, they can choose what activities they prefer to complete, thereby offering users a more 
personalized experience in terms of selecting tracks as well as activities, which has been shown to improve efficacy [101,102]. Although participants will have access to all Happify for Teen tracks, we will feature a track called Stop the Worry Cycle. Each track consists of 4 different parts, and users must complete activities within each part to earn a silver or gold medal before they can move on to the next part. Users can also complete activities on demand through instant play and can switch tracks at any time.

Participants will not be given explicit instructions on how often they should use the platform or how many activities to complete; however, we will encourage them to engage with the platform daily. Participants will also receive push notifications on their mobile device every other day to remind them to access the platform, and they will receive weekly emails as part of the Happify Health platform to help increase engagement. If a participant has not completed any activities within the platform for 7 days, they will also receive an email or text message (based on participant preferences) from a member of the research team to check in. After the 8-week intervention period, participants in the intervention group will continue to have access to the Happify for Teens platform until the 12-week assessment but will receive no explicit instructions or no push notifications to use the program following the intervention period. We will also no longer track use to contact participants who have not used the program during this 1-month period.

Figure 2. Screenshot of track description for "Stress Buster 101" track in Happify for Teens.

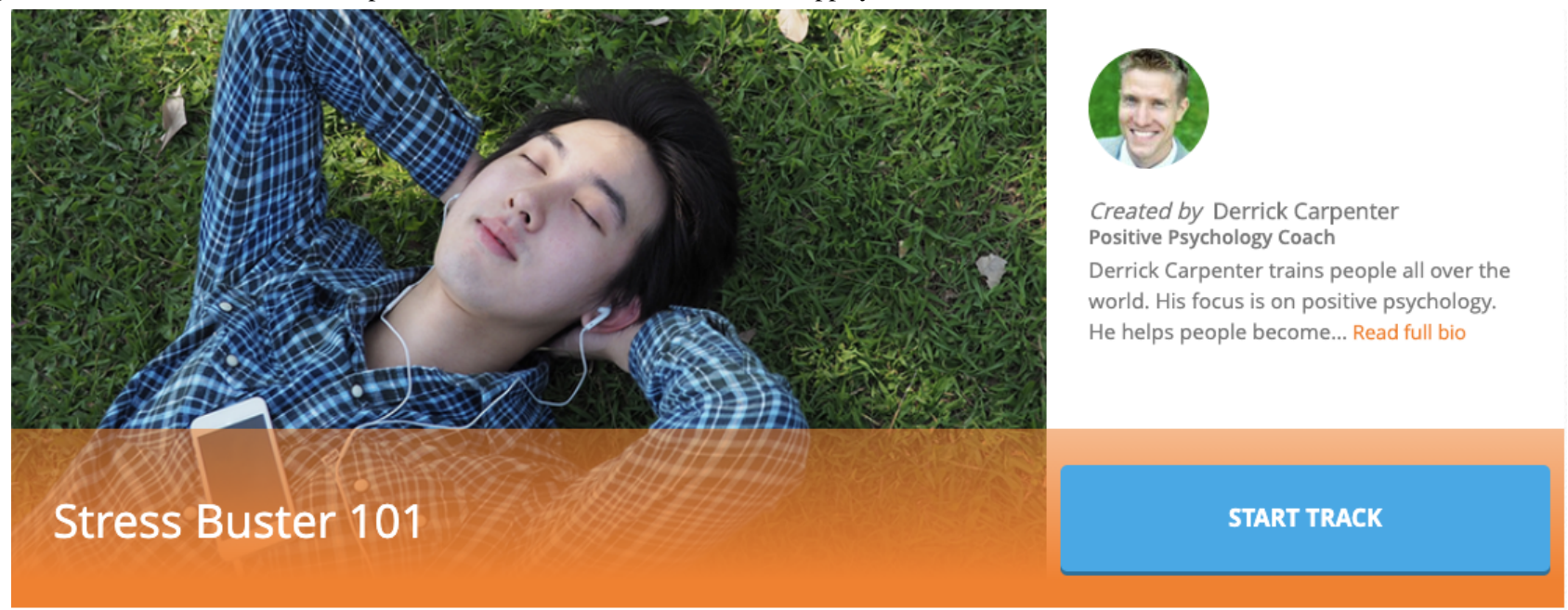

This track can help you:

- Reduce stress and bounce back

- Improve your mindset

- Feel better about your life

Leave stress behind.

Do you know how much stress can affect your health? It can cause you to get sick more often. It can cause you to gain weight. It can even make your body age faster. Yikes!

What you may not know is that there are proven ways to cope with stress. You can develop the skills to manage it. This will help you reach higher levels of happiness.

One fact to think about: $85 \%$ of what you stress about never happens!

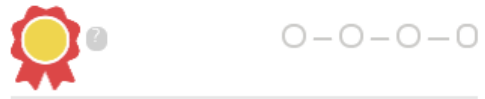

Evidence-based modalities in this track: ??

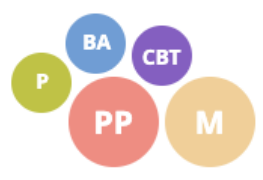

\section{Wait-list Control Group}

Active intervention or Happify Health for Teens will be compared with a wait-list control condition. Participants assigned to this condition will be instructed via email that they have been assigned to a wait-list control and that they will be given access to the Happify for Teens platform after the 12-week study period; however, they are still expected to complete the study assessments. 


\section{Data Analysis}

\section{Changes in Perceived Stress and Secondary or Exploratory Outcomes}

To assess whether changes in participants' perceived stress differed across the 2 groups, we plan to conduct a 2 (group: intervention vs control) $\times 4$ (time: baseline, 4 weeks, 8 weeks, and 12 weeks) repeated-measures ANOVA (Analysis of Variance) on participants' PSS scores, controlling for participant age, gender, and race. Similar analyses will be conducted on the secondary and exploratory outcome measures. In addition, to determine whether usage predicted changes in these outcomes, we will also conduct regression analyses among participants in the intervention condition, regressing their scores on each outcome variable on the number of activities completed within the Happify for Teens platform, while controlling for corresponding baseline scores on that outcome.

\section{Rumination as a Potential Mediator}

To test whether any observed changes in perceived stress can be attributed to changes in brooding, we also plan to conduct mediation analyses using Hayes PROCESS macro for SPSS [103].

\section{Data Exclusion}

As careless responding is problematic with web-based surveys and may artificially increase relationships among variables [104], we plan to use 2 separate a priori mechanisms to identify low-quality data: (1) failing 3 or more attention checks in an assessment and (2) completing an assessment at a rate faster than 1 second per item [104]. We will then rerun the analyses described above without these participants to determine whether any effects differ after removing low-quality data.

\section{Results}

Recruitment is expected to begin during the second quarter of 2021 and will continue until 800 participants have been randomized to one of the two conditions. Participants will begin the 8-week intervention after being screened and consenting to participate; therefore, the first wave of data collection is expected 8 weeks after recruitment begins. We estimate that all participants will complete the intervention in the third quarter of 2021, with final completion, including the 1-month follow-up, by the end of the third quarter of 2021. Given uncertainty regarding attrition and use in an adolescent population, if fewer than 200 participants complete the postintervention assessment, we plan to conduct a second round of recruitment to increase our sample size to ensure adequate power.

\section{Discussion}

Recent data indicate that adolescents are experiencing increasing levels of stress, particularly in school, when their stress levels exceed those of adults [29]. Given that chronic stress predicts a host of psychological, behavioral, and physical problems in adolescence [28,32-38], developing opportunities to help adolescents cope with their stress has become increasingly important [29].
Several interventions for adolescent stress have been developed; however, the evidence supporting their effectiveness is mixed [41-43]. Many of these interventions rely on traditional approaches to treating stress, including stress management training, relaxation training, and problem-solving and decision-making skills training [41,42]; however, these approaches may not adequately address negative cognitions that contribute to perceived stress [44]. For example, rumination, or maladaptive patterns of moody pondering, contributes to perceived stress $[59,60]$ and exacerbates the negative consequences of stress [57,58]. Therefore, interventions may be particularly effective when they also incorporate approaches to addressing negative cognitions, such as cognitive restructuring and acceptance strategies [16]. To our knowledge, this is the first study to examine the effects of a stress management program on both perceived stress and rumination in adolescence and to explore whether changes in rumination mediate the effects of the program on stress.

\section{Evaluating the Efficacy of a Digital Prevention Intervention}

Currently, most stress management programs for adolescents continue to be delivered within schools [41-43]. Although school-based prevention programs can be effective $[42,43]$, there are numerous barriers to implementing evidence-based interventions within schools, including lack of time and resources and financial constraints [105]. Costs associated with implementing such interventions may be particularly prohibitive to schools in socially and economically disadvantaged areas [42], where students may need these interventions the most [41]. Targeted mental health interventions may have additional barriers to student participation due to fear of stigmatization [106]. Given that $95 \%$ of American adolescents own or have access to a cellular phone and $88 \%$ have daily access to a computer [107], a digital intervention addressing stress could offer a better, and arguably more cost-effective, opportunity to reach more adolescents. In addition, participation in the program would not require an entire school to buy-in; therefore, the decision to participate would be individual and private, potentially reducing concerns with stigma as well.

Although mobile mental health apps have become increasingly popular [108], mobile apps developed specifically for youth are still relatively scarce [109]. Furthermore, despite the popularity of mobile mental health apps, high quality empirical research on these apps in general is lacking [109-111]. For example, in a review of mobile mental health apps listed in the National Health Service app library, approximately $28 \%$ of mobile apps for managing depression and anxiety provided evidence to support their effectiveness claims, and only $14 \%$ of apps used validated clinical outcomes to do so [112]. Moreover, the market for these mobile apps is volatile, with one depression-focused app disappearing from the marketplace every 3 days, on average [113]. Early and robust tests of these platforms are therefore an important and necessary step to legitimize digital interventions and mobile mental health apps [114].

Empirical tests of digital interventions are particularly important with regard to platforms developed specifically for youth, as it is less clear how adolescents will respond to these interventions. 
Some research suggests that adolescents prefer therapy when delivered digitally rather than face-to-face [115]. However, other research suggests that adolescents report high internet and mobile app use in general but low use of mental health apps specifically [116]. Some adolescents also report feelings of being labeled and stigmatized if using a digital mental health intervention, even if no one is aware that they are using one [117]. In particular, when considering stress, adolescents tend to believe that stress has little effect on their mental health and rarely engage in stress management on their own [29]. Many studies testing digital interventions in adolescence have aimed to address poor engagement by including some degree of therapist guidance [118], phone contact [119], and physician involvement [120]; however, the effects of these strategies are inconclusive [90]. Consequently, although several studies have demonstrated the effectiveness of the general Happify Health platform with adults [78-81,92], the extent to which adolescents will engage with the digital platform, and in turn, the extent to which they will benefit from the program, is difficult to predict.

\section{Strengths and Limitations}

Research on adolescent interventions has been characterized by low power. Although some studies of school-based stress management interventions have had large samples, a meta-analysis of 54 studies reported that $52 \%$ of the included studies had fewer than 100 participants and $72 \%$ had fewer than 200 participants [41]. Studies on digital interventions have comparatively smaller samples. For example, meta-analyses of studies on digital interventions and mobile mental health apps reported sample sizes ranging from 2 to 206 participants [90,109]. Given the mixed findings in previous research, particularly with stress management interventions [41,42], studies with larger sample sizes are needed to clarify the effectiveness of these interventions. Considering the high dropout rates with digital interventions in general [81,82,121-123], and specifically with adolescents [90,91], this study was designed to be adequately powered even with $75 \%$ attrition.

Another limitation of previous research is that the focus on school-based interventions likely results in samples that are geographically bound to schools in which these programs can be delivered, which may reduce the generalizability of those results. By comparison, testing a digital program that is accessible on adolescents' personal computers or smartphones eliminates many barriers of school-based research, which may result in a more diverse and representative sample of adolescents.

However, our participants may differ from the general population in other ways. First, as we are advertising the study to existing Happify Health users and within specific schools that expressed an interest in the Happify Health platform, our sample may not be representative of the general adolescent population in the United States. Although this may limit the generalizability of our findings to the general population, our recruitment strategy is likely to yield a sample that is representative of Happify Health users, and consequently, our findings should be more representative of our population of

interest: adolescents who will be interested in using the Happify Health platform.

In addition, with the goal of increasing retention and use, we require participants to complete the baseline assessment before qualifying for the study, and we plan to contact participants when they have not engaged with the platform or have not completed an assessment for 7 days. Consequently, our sample may include adolescents who are particularly motivated and conscientious. In addition, because we are advertising to caregivers, adolescents who participate in the study may also differ from the general population in terms of attachment style, quality of relationship with their caregiver, parenting styles, or even the caregiver's own mental health. All these factors could affect the extent to which adolescents respond to the program $[124,125]$.

Our sample also represents adolescents who report elevated levels of both perceived stress and brooding; therefore, it will remain unclear whether Happify for Teens would be effective as a universal stress management program (ie, for adolescents in general). Similarly, whether Happify for Teens would be effective for adolescents with either elevated levels of perceived stress or rumination, rather than elevated levels of both, will also remain unclear. Although this limits generalizability, targeted programs tend to have stronger effects than universal programs [126], and school-based stress management programs appear to be effective only with selective samples [41]. Therefore, we felt it was important to first examine whether Happify for Teens is effective as a targeted program. Arguably, given that adolescents with higher levels of perceived stress and rumination also have a higher risk of developing more severe impairment without intervention [23,24,50,52], a targeted approach also helps to test efficacy more robustly in the population that needs the program the most. Nevertheless, future research should test the effect of this program with a less selective sample of adolescents.

Previous research on digital adolescent mental health interventions has also been criticized for a lack of follow-up assessments [90,127,128]; however, some interventions, including school-based stress management interventions, may have stronger effects over time than immediately post intervention [41], emphasizing the importance of long-term follow-up. This study includes a 1-month follow-up, providing some insight into the longitudinal effects of the program, but future research should include more long-term follow-up to better ascertain whether effects diminish or strengthen over time. In addition, although reducing perceived stress and rumination should reduce participants' likelihood of developing mental health problems, such as depression and anxiety, further research is needed to assess the long-term implications of Happify for Teens on other mental or physical health outcomes.

\section{Conclusions}

Adolescent mental health is a growing area of concern, as many mental health problems begin in adolescence and continue into adulthood [5,6]. Prevention interventions offer a means of promoting mental health among youth before more serious dysfunction or impairment becomes an issue, thereby reducing the likelihood of mental health disorders and associated chronic 
disorders [2,13]. Such interventions are not only effective [2,17-22] but may also help reduce the burden on mental health services from adolescents with little to no impairment [13], who represent an increasing proportion of adolescents seeking services [9]. These interventions are most effective when they target samples with a higher risk of mental health problems $[2,41]$ and address transdiagnostic risk factors [15,16]. Stress is an important transdiagnostic risk factor that has been studied primarily in the context of school-based stress management programs [41-43] and without considering underlying negative cognitions that might contribute to perceived stress and exacerbate the negative effects of that stress [39,44,57-60]. This trial tests a novel digital stress management program for adolescents and its effects on perceived stress and rumination. These data will, therefore, provide important information about the potential efficacy of a more scalable and cost-effective method of improving perceived stress and other associated outcomes in an adolescent population.

\section{Authors' Contributions}

EMB contributed to designing the study and wrote the initial draft of this protocol. HEW contributed to designing the study and to writing the protocol. JLS contributed to designing the study and provided general manuscript support for this protocol. ACP contributed substantially to the study aims, scope, and design of the study.

\section{Conflicts of Interest}

EMB, HEW, and ACP are employees of Happify Health. JLS was employed by Happify Health when the study was designed and this protocol was written.

\section{References}

1. Whitney DG, Peterson MD. US national and state-level prevalence of mental health disorders and disparities of mental health care use in children. JAMA Pediatr 2019 Apr 01;173(4):389-391 [FREE Full text] [doi:

10.1001/jamapediatrics.2018.5399] [Medline: 30742204]

2. Kieling C, Baker-Henningham H, Belfer M, Conti G, Ertem I, Omigbodun O, et al. Child and adolescent mental health worldwide: evidence for action. The Lancet 2011 Oct;378(9801):1515-1525 [FREE Full text] [doi: 10.1016/s0140-6736(11)60827-1]

3. Twenge JM, Cooper A, Joiner T, Duffy M, Binau S. Age, period, and cohort trends in mood disorder indicators and suicide-related outcomes in a nationally representative dataset, 2005-2017. J Abnorm Psychol 2019 Apr;128(3):185-199 [FREE Full text] [doi: 10.1037/abn0000410] [Medline: $\underline{\text { 30869927] }}$

4. Olfson M, Blanco C, Wang S, Laje G, Correll C. National trends in the mental health care of children, adolescents, and adults by office-based physicians. JAMA Psychiatry 2014 Jan;71(1):81-90 [FREE Full text] [doi: 10.1001/jamapsychiatry.2013.3074] [Medline: 24285382]

5. Kessler RC, Berglund P, Demler O, Jin R, Merikangas KR, Walters EE. Lifetime prevalence and age-of-onset distributions of DSM-IV disorders in the National Comorbidity Survey Replication. Arch Gen Psychiatry 2005 Jun;62(6):593-602. [doi: 10.1001/archpsyc.62.6.593] [Medline: 15939837]

6. Kessler RC, Angermeyer M, Anthony J, DE Graaf R, Demyttenaere K, Gasquet I, et al. Lifetime prevalence and age-of-onset distributions of mental disorders in the World Health Organization's World Mental Health Survey Initiative. World Psychiatry 2007 Oct;6(3):168-176 [FREE Full text] [Medline: 18188442]

7. Merikangas KR, He J, Burstein M, Swendsen J, Avenevoli S, Case B, et al. Service utilization for lifetime mental disorders in U.S. adolescents: results of the National Comorbidity Survey-Adolescent Supplement (NCS-A). J Am Acad Child Adolesc Psychiatry 2011 Jan;50(1):32-45 [FREE Full text] [doi: 10.1016/j.jaac.2010.10.006] [Medline: 21156268]

8. Essau CA. Frequency and patterns of mental health services utilization among adolescents with anxiety and depressive disorders. Depress Anxiety 2005;22(3):130-137. [doi: 10.1002/da.20115] [Medline: 16175563]

9. Olfson M, Druss BG, Marcus SC. Trends in mental health care among children and adolescents. N Engl J Med 2015 May 21;372(21):2029-2038. [doi: 10.1056/nejmsa1413512]

10. Thomas CR, Holzer CE. The continuing shortage of child and adolescent psychiatrists. J Am Acad Child Adolesc Psychiatry 2006 Sep;45(9):1023-1031. [doi: 10.1097/01.chi.0000225353.16831.5d] [Medline: 16840879]

11. Galderisi S, Heinz A, Kastrup M, Beezhold J, Sartorius N. Toward a new definition of mental health. World Psychiatry 2015 Jun 04;14(2):231-233 [FREE Full text] [doi: 10.1002/wps.20231] [Medline: 26043341]

12. Keyes CLM. The mental health continuum: from languishing to flourishing in life. J Health Soc Behav 2002 Jun;43(2):207. [doi: 10.2307/3090197]

13. Kazdin AE. Adolescent mental health: prevention and treatment programs. Am Psycho 1993;48(2):127-141. [doi: 10.1037/0003-066x.48.2.127]

14. Egan SJ, Wade TD, Shafran R. Perfectionism as a transdiagnostic process: a clinical review. Clin Psychol Rev 2011;31(2):203-212. [doi: 10.1016/j.cpr.2010.04.009] [Medline: 20488598]

15. Nehmy TJ. School-based prevention of depression and anxiety in Australia: current state and future directions. Clin Psychol 2010 Nov 05;14(3):74-83. [doi: 10.1080/13284207.2010.524884] 
16. Dozois DJA, Seeds PM, Collins KA. Transdiagnostic approaches to the prevention of depression and anxiety. J Cogn Psychother 2009 Feb 01;23(1):44-59. [doi: 10.1891/0889-8391.23.1.44]

17. Skeen S, Laurenzi CA, Gordon SL, du Toit S, Tomlinson M, Dua T, et al. Adolescent mental health program components and behavior risk reduction: a meta-analysis. Pediatrics 2019 Aug 01;144(2) [FREE Full text] [doi: 10.1542/peds.2018-3488] [Medline: $\underline{31262779}$ ]

18. Dray J, Bowman J, Campbell E, Freund M, Wolfenden L, Hodder RK, et al. Systematic review of universal resilience-focused interventions targeting child and adolescent mental health in the school setting. J Am Acad Child Adolesc Psychiatry 2017 Oct;56(10):813-824 [FREE Full text] [doi: 10.1016/j.jaac.2017.07.780] [Medline: 28942803]

19. Shoshani A, Steinmetz S. Positive psychology at school: a school-based intervention to promote adolescents' mental health and well-being. J Happiness Stud 2013 Sep 24;15(6):1289-1311. [doi: 10.1007/s10902-013-9476-1]

20. Hetrick SE, Cox GR, Witt KG, Bir JJ, Merry SN. Cognitive behavioural therapy (CBT), third-wave CBT and interpersonal therapy (IPT) based interventions for preventing depression in children and adolescents. Cochrane Database Syst Rev 2016 Aug 09(8). [doi: 10.1002/14651858.CD003380.pub4] [Medline: 27501438]

21. Rasing SPA, Creemers DHM, Janssens JMAM, Scholte RHJ. Depression and anxiety prevention based on cognitive behavioral therapy for at-risk adolescents: a meta-analytic review. Front Psychol 2017;8:1066 [FREE Full text] [doi: 10.3389/fpsyg.2017.01066] [Medline: 28701980]

22. Kumar GV, Sebastian L. Impact of CBT on self efficacy and academic achievement in adolescent students. J Indian Acad Appl Psychol. 2011. URL: https://www.researchgate.net/publication/

288363105_Impact_of_CBT_on_self_efficacy_and_academic_achievement_in_adolescent_students [accessed 2021-03-17]

23. Wang S, Zhao Y, Zhang L, Wang X, Wang X, Cheng B, et al. Stress and the brain: perceived stress mediates the impact of the superior frontal gyrus spontaneous activity on depressive symptoms in late adolescence. Hum Brain Mapp 2019 Dec 01;40(17):4982-4993 [FREE Full text] [doi: 10.1002/hbm.24752] [Medline: 31397949]

24. Lathren C, Bluth K, Park J. Adolescent self-compassion moderates the relationship between perceived stress and internalizing symptoms. Pers Individ Dif 2019 Jun 01;143:36-41 [FREE Full text] [doi: 10.1016/j.paid.2019.02.008] [Medline: 32042216]

25. Conway CC, Raposa EB, Hammen C, Brennan PA. Transdiagnostic pathways from early social stress to psychopathology: a 20-year prospective study. J Child Psychol Psychiatry 2018 Aug 08;59(8):855-862. [doi: 10.1111/jcpp.12862] [Medline: 29315560]

26. Romeo RD. The teenage brain: the stress response and the adolescent brain. Curr Dir Psychol Sci 2013 Apr 16;22(2):140-145 [FREE Full text] [doi: 10.1177/0963721413475445] [Medline: 25541572]

27. Suo L, Zhao L, Si J, Liu J, Zhu W, Chai B, et al. Predictable chronic mild stress in adolescence increases resilience in adulthood. Neuropsychopharmacology 2013 Jul 11;38(8):1387-1400 [FREE Full text] [doi: 10.1038/npp.2013.67] [Medline: 23478858]

28. Østerås B, Sigmundsson H, Haga M. Perceived stress and musculoskeletal pain are prevalent and significantly associated in adolescents: an epidemiological cross-sectional study. BMC Public Health 2015 Oct 23;15:1081 [FREE Full text] [doi: 10.1186/s12889-015-2414-x] [Medline: 26498498]

29. Stress in America: are teens adopting adults' stress habits? American Psychological Association. 2014. URL: https://www. apa.org/news/press/releases/stress/2013/stress-report.pdf [accessed 2020-10-29]

30. Suldo SM, Shaunessy E, Thalji A, Michalowski J, Shaffer E. Sources of stress for students in high school college preparatory and general education programs: group differences and associations with adjustment. Adolescence 2009;44(176):925-948. [Medline: 20432608]

31. Anniko MK, Boersma K, Tillfors M. Sources of stress and worry in the development of stress-related mental health problems: a longitudinal investigation from early- to mid-adolescence. Anxiety Stress Coping 2019 Mar 22;32(2):155-167. [doi: 10.1080/10615806.2018.1549657] [Medline: 30465445]

32. Burger K, Samuel R. The role of perceived stress and self-efficacy in young people's life satisfaction: a longitudinal study. J Youth Adolesc 2017 Jan 3;46(1):78-90. [doi: 10.1007/s10964-016-0608-x] [Medline: 27812840]

33. DuBois DL, Felner RD, Brand S, Adan AM, Evans EG. A prospective study of life stress, social support, and adaptation in early adolescence. Child Development 1992 Jun;63(3):542. [doi: 10.2307/1131345]

34. Kaplan DS, Liu RX, Kaplan HB. School related stress in early adolescence and academic performance three years later: the conditional influence of self expectations. Soc Psychol Educ 2005 Mar;8(1):3-17. [doi: 10.1007/s11218-004-3129-5]

35. Wills TA, Sandy JM, Yaeger AM. Stress and smoking in adolescence: a test of directional hypotheses. Health Psychol 2002;21(2):122-130. [doi: 10.1037/0278-6133.21.2.122]

36. Nguyen-Rodriguez ST, Chou CP, Unger JB, Spruijt-Metz D. BMI as a moderator of perceived stress and emotional eating in adolescents. Eat Behav 2008 Apr;9(2):238-246 [FREE Full text] [doi: 10.1016/j.eatbeh.2007.09.001] [Medline: 18329603]

37. De Vriendt T, Clays E, Huybrechts I, De Bourdeaudhuij I, Moreno LA, Patterson E, et al. European adolescents' level of perceived stress is inversely related to their diet quality: the Healthy Lifestyle in Europe by Nutrition in Adolescence study. Br J Nutr 2011 Nov 04;108(2):371-380. [doi: 10.1017/s0007114511005708]

38. Wiklund M, Malmgren-Olsson E, Ohman A, Bergström E, Fjellman-Wiklund A. Subjective health complaints in older adolescents are related to perceived stress, anxiety and gender - a cross-sectional school study in Northern Sweden. BMC Public Health 2012 Nov 16;12(1):993 [FREE Full text] [doi: 10.1186/1471-2458-12-993] [Medline: 23158724] 
39. Carter JS, Garber J. Predictors of the first onset of a major depressive episode and changes in depressive symptoms across adolescence: stress and negative cognitions. J Abnorm Psychol 2011 Nov;120(4):779-796. [doi: 10.1037/a0025441] [Medline: 21928863]

40. Cohen S, Kamarck T, Mermelstein R. A global measure of perceived stress. J Health Soc Behav 1983;24(4):385. [doi: $10.2307 / 2136404]$

41. van Loon AWG, Creemers HE, Beumer WY, Okorn A, Vogelaar S, Saab N, et al. Can schools reduce adolescent psychological stress? A multilevel meta-analysis of the effectiveness of school-based intervention programs. J Youth Adolesc 2020 Jun 7;49(6):1127-1145 [FREE Full text] [doi: 10.1007/s10964-020-01201-5] [Medline: 32034632]

42. Feiss R, Dolinger SB, Merritt M, Reiche E, Martin K, Yanes JA, et al. A systematic review and meta-analysis of school-based stress, anxiety, and depression prevention programs for adolescents. J Youth Adolesc 2019 Sep 26;48(9):1668-1685 [FREE Full text] [doi: 10.1007/s10964-019-01085-0] [Medline: 31346924]

43. Rew L, Johnson K, Young C. A systematic review of interventions to reduce stress in adolescence. Issues Ment Health Nurs 2014 Nov 29;35(11):851-863. [doi: 10.3109/01612840.2014.924044] [Medline: 25353298]

44. Lindahl M, Archer T. Depressive expression and anti-depressive protection in adolescence: stress, positive affect, motivation and self-efficacy. Psychol 2013;04(06):495-505. [doi: 10.4236/psych.2013.46070]

45. Kuhlman KR, Chiang JJ, Bower JE, Irwin MR, Cole SW, Dahl RE, et al. Persistent low positive affect and sleep disturbance across adolescence moderate link between stress and depressive symptoms in early adulthood. J Abnorm Child Psychol 2020 Jan 24;48(1):109-121. [doi: 10.1007/s10802-019-00581-y] [Medline: $\underline{31446530}$ ]

46. Smith JM, Alloy LB. A roadmap to rumination: a review of the definition, assessment, and conceptualization of this multifaceted construct. Clin Psychol Rev 2009 Mar;29(2):116-128 [FREE Full text] [doi: 10.1016/j.cpr.2008.10.003] [Medline: 19128864$]$

47. Treynor W, Gonzalez R, Nolen-Hoeksema S. Rumination reconsidered: a psychometric analysis. Cognit Ther Res 2003;27(3):247-259. [doi: 10.1023/A:1023910315561]

48. Mazzer K, Boersma K, Linton SJ. A longitudinal view of rumination, poor sleep and psychological distress in adolescents. J Affect Disord 2019 Feb 15;245:686-696. [doi: 10.1016/j.jad.2018.11.053] [Medline: 30447567]

49. Topper M, Emmelkamp PM, Watkins E, Ehring T. Prevention of anxiety disorders and depression by targeting excessive worry and rumination in adolescents and young adults: a randomized controlled trial. Behav Res Ther 2017 Mar;90:123-136. [doi: 10.1016/j.brat.2016.12.015] [Medline: 28049069]

50. Burwell RA, Shirk SR. Subtypes of rumination in adolescence: associations between brooding, reflection, depressive symptoms, and coping. J Clin Child Adolesc Psychol 2007 Mar;36(1):56-65. [doi: 10.1080/15374410709336568] [Medline: 17206881]

51. Hankin BL. Rumination and depression in adolescence: investigating symptom specificity in a multiwave prospective study. J Clin Child Adolesc Psychol 2008 Oct 07;37(4):701-713 [FREE Full text] [doi: 10.1080/15374410802359627] [Medline: 18991122]

52. Jose PE, Weir KF. How is anxiety involved in the longitudinal relationship between brooding rumination and depressive symptoms in adolescents? J Youth Adolesc 2013 Aug 25;42(8):1210-1222. [doi: 10.1007/s10964-012-9891-3] [Medline: 23266617]

53. Connolly SL, Wagner CA, Shapero BG, Pendergast LL, Abramson LY, Alloy LB. Rumination prospectively predicts executive functioning impairments in adolescents. J Behav Ther Exp Psychiatry 2014 Mar;45(1):46-56 [FREE Full text] [doi: 10.1016/j.jbtep.2013.07.009] [Medline: 23978629]

54. Willem L, Bijttebier P, Claes L, Raes F. Rumination subtypes in relation to problematic substance use in adolescence. Pers Individ Differ 2011 Apr;50(5):695-699. [doi: 10.1016/j.paid.2010.12.020]

55. Jenness JL, Jager-Hyman S, Heleniak C, Beck AT, Sheridan MA, McLaughlin KA. Catastrophizing, rumination, and reappraisal prospectively predict adolescent PTSD symptom onset following a terrorist attack. Depress Anxiety 2016 Nov 24;33(11):1039-1047 [FREE Full text] [doi: 10.1002/da.22548] [Medline: 27557454]

56. Michl LC, McLaughlin KA, Shepherd K, Nolen-Hoeksema S. Rumination as a mechanism linking stressful life events to symptoms of depression and anxiety: longitudinal evidence in early adolescents and adults. J Abnorm Psychol 2013 May;122(2):339-352 [FREE Full text] [doi: 10.1037/a0031994] [Medline: 23713497]

57. Skitch SA, Abela JRZ. Rumination in response to stress as a common vulnerability factor to depression and substance misuse in adolescence. J Abnorm Child Psychol 2008 Oct 7;36(7):1029-1045. [doi: 10.1007/s10802-008-9233-9] [Medline: $\underline{18461438}]$

58. Connolly SL, Alloy LB. Rumination interacts with life stress to predict depressive symptoms: an ecological momentary assessment study. Behav Res Ther 2017 Oct;97:86-95 [FREE Full text] [doi: 10.1016/j.brat.2017.07.006] [Medline: 28734979]

59. Marks AD, Sobanski DJ, Hine DW. Do dispositional rumination and/or mindfulness moderate the relationship between life hassles and psychological dysfunction in adolescents? Aust N Z J Psychiatry 2010 Sep;44(9):831-838. [doi: 10.3109/00048674.2010.487478] [Medline: 20815670] 
60. McLaughlin KA, Nolen-Hoeksema S. Interpersonal stress generation as a mechanism linking rumination to internalizing symptoms in early adolescents. J Clin Child Adolesc Psychol 2012 Sep;41(5):584-597 [FREE Full text] [doi: 10.1080/15374416.2012.704840] [Medline: 22867280]

61. Svendsen JL, Kvernenes KV, Wiker AS, Dundas I. Mechanisms of mindfulness: rumination and self-compassion. Nordic Psychol 2016 Apr 15;69(2):71-82. [doi: 10.1080/19012276.2016.1171730]

62. Edwards M, Adams EM, Waldo M, Hadfield OD, Biegel GM. Effects of a mindfulness group on latino adolescent students: examining levels of perceived stress, mindfulness, self-compassion, and psychological symptoms. J Spec Group Work 2014 Mar 13;39(2):145-163. [doi: 10.1080/01933922.2014.891683]

63. Samaie G, Farahani HA. Self-compassion as a moderator of the relationship between rumination, self-reflection and stress. Procedia Soc Behav 2011;30:978-982. [doi: 10.1016/j.sbspro.2011.10.190]

64. Galla BM. Within-person changes in mindfulness and self-compassion predict enhanced emotional well-being in healthy, but stressed adolescents. J Adolesc 2016 Jun;49:204-217. [doi: 10.1016/j.adolescence.2016.03.016] [Medline: 27107398]

65. Bessette KL, Jacobs RH, Heleniak C, Peters AT, Welsh RC, Watkins ER, et al. Malleability of rumination: an exploratory model of CBT-based plasticity and long-term reduced risk for depressive relapse among youth from a pilot randomized clinical trial. PLoS One 2020 Jun 17;15(6) [FREE Full text] [doi: 10.1371/journal.pone.0233539] [Medline: 32555582]

66. Hamdan-Mansour AM, Puskar K, Bandak AG. Effectiveness of cognitive-behavioral therapy on depressive symptomatology, stress and coping strategies among Jordanian university students. Issues Ment Health Nurs 2009 Mar 09;30(3):188-196. [doi: 10.1080/01612840802694577] [Medline: 19291496$]$

67. Beck AT, Rush AJ, Shaw BF, Emery G. Cognitive therapy of depression. New York: Guilford Press; 1979.

68. Praissman S. Mindfulness-based stress reduction: a literature review and clinician's guide. J Am Acad Nurse Pract 2008 Apr;20(4):212-216. [doi: 10.1111/j.1745-7599.2008.00306.x] [Medline: 18387018]

69. Seligman MEP, Csikszentmihalyi M. Positive psychology: an introduction. Am Psychol 2000;55(1):5-14. [doi: 10.1037//0003-066x.55.1.5]

70. Duckworth AL, Steen TA, Seligman ME. Positive psychology in clinical practice. Annu Rev Clin Psychol 2005 Apr;1(1):629-651. [doi: 10.1146/annurev.clinpsy.1.102803.144154] [Medline: 17716102]

71. Seligman MEP, Steen TA, Park N, Peterson C. Positive psychology progress: empirical validation of interventions. Am Psychol 2005;60(5):410-421. [doi: 10.1037/0003-066x.60.5.410]

72. Hopko DR, Lejuez CW, Ruggiero KJ, Eifert GH. Contemporary behavioral activation treatments for depression: procedures, principles, and progress. Clin Psychol Rev 2003 Oct;23(5):699-717. [doi: 10.1016/s0272-7358(03)00070-9]

73. Kanter JW, Manos RC, Bowe WM, Baruch DE, Busch AM, Rusch LC. What is behavioral activation? A review of the empirical literature. Clin Psychol Rev 2010 Aug;30(6):608-620. [doi: 10.1016/j.cpr.2010.04.001] [Medline: 20677369]

74. Hayes SC, Luoma JB, Bond FW, Masuda A, Lillis J. Acceptance and commitment therapy: model, processes and outcomes. Behav Res Ther 2006 Jan;44(1):1-25. [doi: 10.1016/j.brat.2005.06.006] [Medline: 16300724]

75. Lukens EP, McFarlane WR. Psychoeducation as evidence-based practice: considerations for practice, research, and policy. Brief Treat Crisis Interv 2004;4(3). [doi: 10.1093/brief-treatment/mhh019]

76. Brinkborg H, Michanek J, Hesser H, Berglund G. Acceptance and commitment therapy for the treatment of stress among social workers: a randomized controlled trial. Behav Res Ther 2011 Jun;49(6-7):389-398. [doi: 10.1016/j.brat.2011.03.009] [Medline: 21513917]

77. Wersebe H, Lieb R, Meyer AH, Hofer P, Gloster AT. The link between stress, well-being, and psychological flexibility during an Acceptance and Commitment Therapy self-help intervention. Int J Clin Health Psychol 2018 Jan;18(1):60-68 [FREE Full text] [doi: 10.1016/j.ijchp.2017.09.002] [Medline: $\underline{30487911]}$

78. Carpenter J, Crutchley P, Zilca RD, Schwartz HA, Smith LK, Cobb AM, et al. Seeing the "Big" picture: Big Data Methods for exploring relationships between usage, language, and outcome in internet intervention data. J Med Internet Res 2016 Aug 31;18(8):e241 [FREE Full text] [doi: 10.2196/jmir.5725] [Medline: 27580524]

79. Carpenter J, Crutchley P, Zilca RD, Schwartz HA, Smith LK, Cobb AM, et al. Correction: seeing the "Big" picture: Big Data Methods for exploring relationships between usage, language, and outcome in internet intervention data. J Med Internet Res 2017 Dec 19;19(12):e347 [FREE Full text] [doi: 10.2196/jmir.8099] [Medline: 29258059]

80. Parks AC, Williams AL, Kackloudis GM, Stafford JL, Boucher EM, Honomichl RD. The effects of a digital well-being intervention on patients with chronic conditions: observational study. J Med Internet Res 2020 Jan 10;22(1) [FREE Full text] [doi: 10.2196/16211] [Medline: $\underline{31922491]}$

81. Parks AC, Williams A, Tugade M, Hokes K, Honomichl R, Zilca R. Testing a scalable web and smartphone based intervention to improve depression, anxiety, and resilience: a randomized controlled trial. Int J Wellbeing 2018 Dec 08;8(2):22-67 [FREE Full text] [doi: 10.5502/ijw.v8i2.745]

82. Williams AL, Parks AC, Cormier G, Stafford J, Whillans AV. Improving resilience among employees high in depression, anxiety, and workplace distress. Int J Hum Resour Manag. 2018. URL: https://www.hbs.edu/faculty/Pages/item. aspx?num=55598 [accessed 2021-03-17]

83. Hunter JF, Olah MS, Williams AL, Parks AC, Pressman SD. Effect of brief biofeedback via a smartphone app on stress recovery: randomized experimental study. JMIR Serious Games 2019 Nov 26;7(4) [FREE Full text] [doi: 10.2196/15974] [Medline: $\underline{31769761]}$ 
84. Harvey AG, Murray G, Chandler RA, Soehner A. Sleep disturbance as transdiagnostic: consideration of neurobiological mechanisms. Clin Psychol Rev 2011 Mar;31(2):225-235 [FREE Full text] [doi: 10.1016/j.cpr.2010.04.003] [Medline: 20471738]

85. Danielsson NS, Harvey AG, Macdonald S, Jansson-Fröjmark M, Linton SJ. Sleep disturbance and depressive symptoms in adolescence: the role of catastrophic worry. J Youth Adolesc 2013 Aug 12;42(8):1223-1233. [doi:

10.1007/s10964-012-9811-6] [Medline: 22968332]

86. Conversano C, Rotondo A, Lensi E, Vista OD, Arpone F, Reda MA. Optimism and its impact on mental and physical well-being. Clin Pract Epidemiol Ment Health 2010 May 14;6(1):25-29 [FREE Full text] [doi: 10.2174/1745017901006010025] [Medline: 20592964]

87. Uribe FAR, Espejo CAN, Pedroso JDS. Role of optimism in adolescent mental health: a protocol for a systematic review. BMJ Open 2020 Jul 07;10(7) [FREE Full text] [doi: 10.1136/bmjopen-2019-036177] [Medline: 32641362]

88. Käll A, Shafran R, Lindegaard T, Bennett S, Cooper Z, Coughtrey A, et al. A common elements approach to the development of a modular cognitive behavioral theory for chronic loneliness. J Consult Clin Psychol 2020 Mar;88(3):269-282 [FREE Full text] [doi: 10.1037/ccp0000454] [Medline: 32068427]

89. Ebesutani C, Fierstein M, Viana A, Trent L, Young J, Sprung M. The role of loneliness in the relationship between anxiety and depression in clinical and school-based youth. Psychol Sch 2015 Jan 12;52(3):223-234 [FREE Full text] [doi: $10.1002 /$ pits.21818]

90. Richardson T, Stallard P, Velleman S. Computerised cognitive behavioural therapy for the prevention and treatment of depression and anxiety in children and adolescents: a systematic review. Clin Child Fam Psychol Rev 2010 Sep;13(3):275-290. [doi: 10.1007/s10567-010-0069-9] [Medline: 20532980]

91. Rose T, Barker M, Maria Jacob C, Morrison L, Lawrence W, Strömmer S, et al. A systematic review of digital interventions for improving the diet and physical activity behaviors of adolescents. J Adolesc Health 2017 Dec;61(6):669-677 [FREE Full text] [doi: 10.1016/j.jadohealth.2017.05.024] [Medline: 28822682]

92. Kechter A, Black DS, Riggs NR, Warren CM, Ritt-Olson A, Chou C, et al. Factors in the perceived stress scale differentially associate with mindfulness disposition and executive function among early adolescents. J Child Fam Stud 2019 Mar 4;28(3):814-821 [FREE Full text] [doi: 10.1007/s10826-018-01313-4] [Medline: 31772488]

93. Andersen JH, Lindholdt L, Winding TN, Lund T, Labriola M. Perceived stress among adolescents is socially determined. Eur J Public Health 2017;19(1). [doi: 10.1093/eurpub/ckx189.108]

94. Xavier A, Cunha M, Pinto-Gouveia J. Rumination in adolescence: the distinctive impact of brooding and reflection on psychopathology. Span J Psychol 2016 Jun 20;19:E37. [doi: 10.1017/sjp.2016.41] [Medline: 27320186]

95. Mezulis A, Simonson J, McCauley E, Stoep AV. The association between temperament and depressive symptoms in adolescence: brooding and reflection as potential mediators. Cogn Emot 2011 Dec;25(8):1460-1470 [FREE Full text] [doi: 10.1080/02699931.2010.543642] [Medline: 21432637]

96. Scheier MF, Carver CS, Bridges MW. Distinguishing optimism from neuroticism (and trait anxiety, self-mastery, and self-esteem): a reevaluation of the Life Orientation Test. J Pers Soc Psychol 1994;67(6):1063-1078. [doi: 10.1037/0022-3514.67.6.1063]

97. Creed PA, Patton W, Bartrum D. Multidimensional Properties of the Lot-R: Effects of Optimism and Pessimism on Career and Well-Being Related Variables in Adolescents. J Career Assess 2016 Jul 25;10(1):42-61. [doi: $10.1177 / 1069072702010001003]$

98. Forrest CB, Meltzer L, Marcus C, de la Motte A, Kratchman A, Buysse DJ, et al. Development and validation of the PROMIS Pediatric Sleep Disturbance and Sleep-Related Impairment item banks. Sleep 2018 Jun 01;41(6). [doi: 10.1093/sleep/zsy054] [Medline: 29546286]

99. Roberts RE, Lewinsohn PM, Seeley JR. A brief measure of loneliness suitable for use with adolescents. Psychol Rep 1993 Jun 31;72(3 Pt 2):1379-1391. [doi: 10.2466/pr0.1993.72.3c.1379] [Medline: $\underline{\text { 8337350] }}$

100. Russell D, Peplau LA, Cutrona CE. The revised UCLA Loneliness Scale: concurrent and discriminant validity evidence. J Pers Soc Psychol 1980 Sep;39(3):472-480. [doi: 10.1037/0022-3514.39.3.472]

101. Lyubomirsky S, Layous K. How do simple positive activities increase well-being? Curr Dir Psychol Sci 2013 Feb 22;22(1):57-62. [doi: 10.1177/0963721412469809]

102. Lyubomirsky S, Sheldon KM, Schkade D. Pursuing happiness: the architecture of sustainable change. Rev Gen Psychol 2005 Jun 01;9(2):111-131. [doi: 10.1037/1089-2680.9.2.111]

103. Hayes AF. Introduction to Mediation, Moderation, and Conditional Process Analysis: A Regression-Based Approach. New York: Guilford publications; 2013.

104. Wood D, Harms PD, Lowman GH, DeSimone JA. Response speed and response consistency as mutually validating indicators of data quality in online samples. Soc Psychol Personal Sci 2017 Jun 07;8(4):454-464. [doi: 10.1177/1948550617703168]

105. Hicks TB, Shahidullah JD, Carlson JS, Palejwala MH. Nationally Certified School Psychologists' use and reported barriers to using evidence-based interventions in schools: the influence of graduate program training and education. Sch Psychol Q 2014 Dec;29(4):469-487. [doi: 10.1037/spq0000059] [Medline: 24708281]

106. Gronholm PC, Nye E, Michelson D. Stigma related to targeted school-based mental health interventions: a systematic review of qualitative evidence. J Affect Disord 2018 Nov;240:17-26. [doi: 10.1016/j.jad.2018.07.023] [Medline: 30041074] 
107. Smartphone access nearly ubiquitous among teens, while having a home computer varies by income. Pew Research Internet on Twitter. URL: https://www.pinterest.at/pin/362750944980887440/ [accessed 2020-10-29]

108. Martínez-Pérez B, de la Torre-Díez I, López-Coronado M. Mobile health applications for the most prevalent conditions by the World Health Organization: review and analysis. J Med Internet Res 2013 Jun 14;15(6):e120 [FREE Full text] [doi: 10.2196/jmir.2600] [Medline: 23770578]

109. Grist R, Porter J, Stallard P. Mental health mobile apps for preadolescents and adolescents: a systematic review. J Med Internet Res 2017 May 25;19(5):e176 [FREE Full text] [doi: 10.2196/jmir.7332] [Medline: 28546138]

110. Donker T, Petrie K, Proudfoot J, Clarke J, Birch M, Christensen H. Smartphones for smarter delivery of mental health programs: a systematic review. J Med Internet Res 2013 Nov 15;15(11):e247 [FREE Full text] [doi: 10.2196/jmir.2791] [Medline: 24240579]

111. Marshall JM, Dunstan DA, Bartik W. Clinical or gimmickal: the use and effectiveness of mobile mental health apps for treating anxiety and depression. Aust N Z J Psychiatry 2020 Jan 25;54(1):20-28. [doi: 10.1177/0004867419876700] [Medline: 31552747]

112. Leigh S, Flatt S. App-based psychological interventions: friend or foe? Evid Based Ment Health 2015 Nov;18(4):97-99. [doi: 10.1136/eb-2015-102203] [Medline: 26459466]

113. Larsen ME, Nicholas J, Christensen H. Quantifying app store dynamics: longitudinal tracking of mental health apps. JMIR Mhealth Uhealth 2016 Aug 09;4(3):e96 [FREE Full text] [doi: 10.2196/mhealth.6020] [Medline: 27507641]

114. Marshall JM, Dunstan DA, Bartik W. Smartphone psychology: new approaches towards safe and efficacious mobile mental health apps. Prof Psychol Res Pr 2020 Jun 02;51(3):214-222. [doi: 10.1037/pro0000278]

115. Sweeney GM, Donovan CL, March S, Forbes Y. Logging into therapy: adolescent perceptions of online therapies for mental health problems. Internet Interv 2019 Mar;15:93-99 [FREE Full text] [doi: 10.1016/j.invent.2016.12.001] [Medline: 30792959]

116. Grist R, Cliffe B, Denne M, Croker A, Stallard P. An online survey of young adolescent girls' use of the internet and smartphone apps for mental health support. BJPsych Open 2018 Jul 25;4(4):302-306 [FREE Full text] [doi: 10.1192/bjo.2018.43] [Medline: 30083383]

117. Fleming T, Merry S, Stasiak K, Hopkins S, Patolo T, Ruru S, et al. The importance of user segmentation for designing digital therapy for adolescent mental health: findings from scoping processes. JMIR Ment Health 2019 May 08;6(5) [FREE Full text] [doi: 10.2196/12656] [Medline: $\underline{31066705]}$

118. Murray K, Schmidt U, Pombo-Carril M, Grover M, Alenya J, Treasure J, et al. Does therapist guidance improve uptake, adherence and outcome from a CD-ROM based cognitive-behavioral intervention for the treatment of bulimia nervosa? Compu Human Beh 2007 Jan;23(1):850-859. [doi: 10.1016/j.chb.2004.11.014]

119. Tillfors M, Andersson G, Ekselius L, Furmark T, Lewenhaupt S, Karlsson A, et al. A randomized trial of internet-delivered treatment for social anxiety disorder in high school students. Cogn Behav Ther 2011 Jun;40(2):147-157. [doi: 10.1080/16506073.2011.555486] [Medline: 25155815]

120. Reid SC, Kauer SD, Hearps SJC, Crooke AHD, Khor AS, Sanci LA, et al. A mobile phone application for the assessment and management of youth mental health problems in primary care: a randomised controlled trial. BMC Fam Pract 2011 Nov 29;12:131 [FREE Full text] [doi: 10.1186/1471-2296-12-131] [Medline: 22123031]

121. Donkin L, Christensen H, Naismith SL, Neal B, Hickie IB, Glozier N. A systematic review of the impact of adherence on the effectiveness of e-therapies. J Med Internet Res 2011 Aug 05;13(3):e52 [FREE Full text] [doi: 10.2196/jmir.1772] [Medline: 21821503]

122. Cuijpers P, van Straten A, Andersson G. Internet-administered cognitive behavior therapy for health problems: a systematic review. J Behav Med 2008 Apr;31(2):169-177 [FREE Full text] [doi: 10.1007/s10865-007-9144-1] [Medline: 18165893]

123. Eysenbach G. The law of attrition. J Med Internet Res 2005 Mar 31;7(1):e11 [FREE Full text] [doi: 10.2196/jmir.7.1.e11] [Medline: 15829473]

124. Melchior M, van der Waerden J. Parental influences on children's mental health: the bad and the good sides of it. Eur Child Adolesc Psychiatry 2016 Aug 25;25(8):805-807. [doi: 10.1007/s00787-016-0891-9] [Medline: 27456961]

125. DeWalt DA, Hink A. Health literacy and child health outcomes: a systematic review of the literature. Pediatrics 2009 Oct 27;124(Supplement 3):265-274. [doi: 10.1542/peds.2009-1162b]

126. Horowitz JL, Garber J. The prevention of depressive symptoms in children and adolescents: A meta-analytic review. Journal of Consulting and Clinical Psychology 2006;74(3):401-415. [doi: 10.1037/0022-006x.74.3.401]

127. Li J, Theng YL, Foo S. Game-based digital interventions for depression therapy: a systematic review and meta-analysis. Cyberpsychol Behav Soc Netw 2014 Aug;17(8):519-527 [FREE Full text] [doi: 10.1089/cyber.2013.0481] [Medline: 24810933]

128. Hollis C, Falconer CJ, Martin JL, Whittington C, Stockton S, Glazebrook C, et al. Annual research review: digital health interventions for children and young people with mental health problems - a systematic and meta-review. J Child Psychol Psychiatry 2017 Apr 10;58(4):474-503. [doi: 10.1111/jcpp.12663] [Medline: 27943285] 


\section{Abbreviations \\ APA: American Psychological Association \\ CBT: cognitive behavioral therapy \\ PSS: Perceived Stress Scale \\ RCT: randomized controlled trial \\ RRS: Ruminative Response Scale}

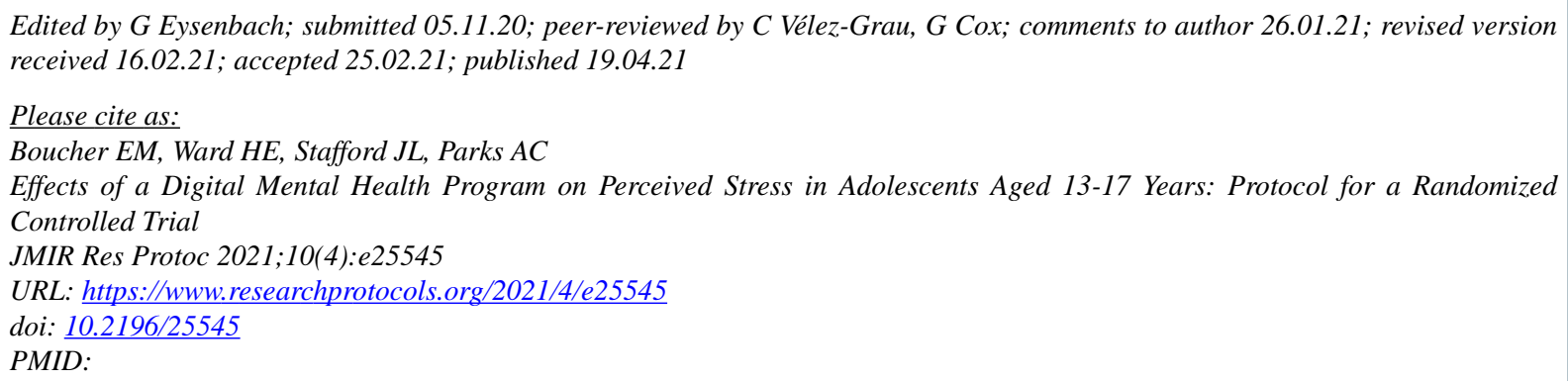

(CEliane M Boucher, Haley E Ward, Julia L Stafford, Acacia C Parks. Originally published in JMIR Research Protocols (https://www.researchprotocols.org), 19.04.2021. This is an open-access article distributed under the terms of the Creative Commons Attribution License (https://creativecommons.org/licenses/by/4.0/), which permits unrestricted use, distribution, and reproduction in any medium, provided the original work, first published in JMIR Research Protocols, is properly cited. The complete bibliographic information, a link to the original publication on http://www.researchprotocols.org, as well as this copyright and license information must be included. 